\section{SAT0508 \\ ACE-INHIBITORS IN ARTERIAL HYPERTENSION IN SSC PATIENTS DISPLAY A RISK FACTOR FOR SCLERODERMA RENAL CRISIS - A EUSTAR ANALYSIS}

S. Adler ${ }^{1}$, P.A. Varisco ${ }^{2}$, O. Distler ${ }^{3}$, L. Buetikofer ${ }^{4}$, O. Kowal-Bielecka ${ }^{5}$, Y. Allanore ${ }^{6}$, G. Riemekasten ${ }^{7}$, P.M. Villiger ${ }^{8} .{ }^{1}$ Rheumatology, University Hospital Bern; ${ }^{2}$ Regional Medical Service, Bern; ${ }^{3}$ University Hospital Zurich, Zurich; ${ }^{4}$ Clinical Trials Unit, Bern, Switzerland; ${ }^{5}$ Warsaw Medical University, Warsaw, Poland; ${ }^{6}$ Cochin Hospital, Paris, France; ${ }^{7}$ University Hospital Schleswig-Holstein, Luebeck, Germany; ${ }^{8}$ University Hospital Bern, Bern, Switzerland

Background: Scleroderma renal crisis (SRC) represents a rare but life-threatening manifestation in systemic sclerosis (SSC). Survival remains poor despite therapeutic use of ACE inhibitors (ACEi). Factors influencing the risk of SRC are not well characterised. In particular, ACEi are discussed as promoting but also as protecting SRC.

Objectives: To investigate the effect of ACEi on SRC incidence in prospectively collected data of a cohort of SSc patients.

Methods: EUSTAR database analysis with focus on arterial hypertension, antihypertensive medication and glucocorticoids. Subgroup analysis of a dataset with defined documentation of medication from January 2009 until November 2017.

Results: Out of 14'524 patients in the database we identified 7'648 patients with at least one follow-up after 2009. 102 patients developed SRC in 27'450 personyears (py), representing an incidence of $3.72(3.06-4.51)$ per 1'000 py. In a multivariable time-to-event analysis adjusted for age, sex, disease severity and onset, arterial hypertension, tendon friction rubs, SCL70 and ACA positivity, 78 of 6083 patients developed SRC. Herein, use of ACEi displayed an increased risk for the development of SRC with a hazard ratio (HR) of 2.07 (95\% confidence interval (Cl):1.28-3.36). Calcium channel blockers (CCB), angiotensin receptor blockers, endothelin receptor antagonists and glucocorticoids did not influence SRC incidence. Medication strategies were not altered after renal crisis. Cumulative mortality 5 years after renal crisis was $18.6 \%(95 \% \mathrm{Cl}: 13.0 \%-26.3 \%)$.
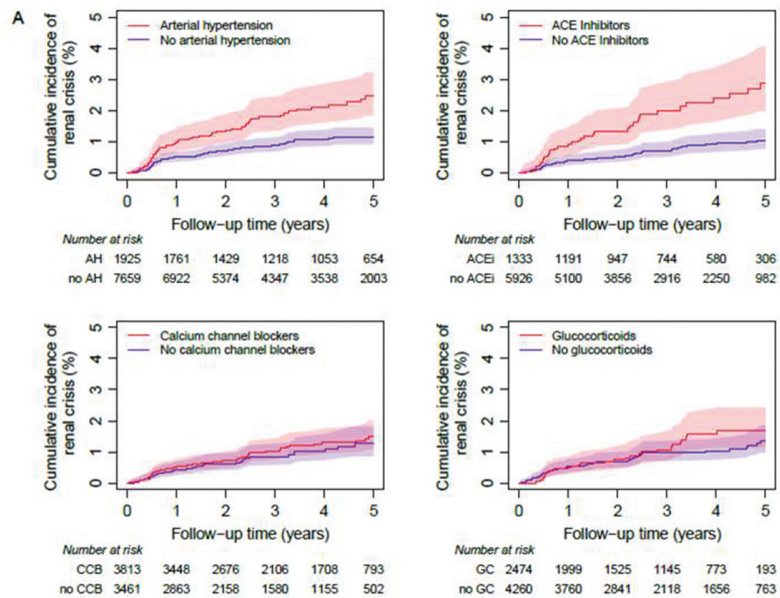

Figure (A) Cumulative incidence plots for scleroderma renal crisis (SRC) depending on whether patients have arterial hypertension (AH), or are treated with ACE inhibitors (ACE), Calcium channel blockers (CCB) or Glucocorticoids (GC).

Conclusions: This EUSTAR analysis supports the notion that ACEi should be avoided in arterial hypertension in SSc patients. Alternative antihypertensive drugs as CCB might be preferred.

\section{REFERENCES:}

[1] Hudson M, Baron M, Tatibouet S, Furst DE, Khanna D, International Scleroderma Renal Crisis Study I. Exposure to ACE inhibitors prior to the onset of scleroderma renal crisis-results from the International Scleroderma Renal Crisis Survey. Seminars in arthritis and rheumatism 2014;43(5):66672.

[2] Guillevin L, Berezne A, Seror R, Teixeira L, Pourrat J, Mahr A, et al. Scleroderma renal crisis: a retrospective multicentre study on 91 patients and 427 controls. Rheumatology (Oxford) 2012;51(3):460-7.

[3] Mouthon L, Bussone G, Berezne A, Noel LH, Guillevin L. Scleroderma renal crisis. The Journal of rheumatology. 2014;41(6):1040-8.
[4] Shanmugam VK, Steen VD. Renal disease in scleroderma: an update on evaluation, risk stratification, pathogenesis and management. Current opinion in rheumatology 2012;24(6):669-76.

Acknowledgements: We acknowledge the work of all participating EUSTAR centres for contributing to this work.

Disclosure of Interest: None declared

DOI: 10.1136/annrheumdis-2018-eular.2384

\section{SAT0509 HOW MONEY SHOULD BE SPENT: PATIENTS PERSPECTIVES ON SCLERODERMA RESEARCH FUNDING}

S. Divani ${ }^{1}$, J. Patel ${ }^{2}$, R. Stratton ${ }^{3} .{ }^{1}$ University College London Medical School;

${ }^{2}$ Homerton University Hospital; ${ }^{3}$ Royal Free Hospital, London, UK

Background: Scleroderma (systemic sclerosis, SSc) is an autoimmune disease that can affect blood vessels, skin and various organs, causing Raynaud's phe nomenon, thickening of skin, gastro-oesophageal reflux and lung fibrosis. Despite remarkable improvements and innovations in management for SSc, leaders in the field continue to believe there is scope for more. ${ }^{1}$ Patients' opinions on future research into the condition and its management, can provide valuable insight on how to shape its prospects and improve outcomes, and how research funding should be best directed. ${ }^{2}$

Objectives: To determine if doctors and patients with scleroderma agree on where future scleroderma research should be focussed.

Methods: 25 patients with scleroderma and 10 doctors were given question naires that asked them to rank 12 issues in order of importance, with a view to directing future Scleroderma research and funding. The highest ranked issue was appointed a score of 12 , and the lowest ranked appointed a score of 1 . The mean scores were calculated, and compared for concordance using ANOVA testing. All patients had been admitted for elective lloprost infusions at Royal Free Hospital and varied in age and gender. The clinicians were of varied levels from FY1 consultant, and all worked in the Rheumatology team at Royal Free.

Results: Patients ranked the issue of "managing Raynaud's symptoms" as the most important, which is significantly different to how clinicians viewed it - patients gave it a ranking 9.8 compared to only 4.9 from clinicians $(p<0.005)$. However doctors placed more value on "avoiding organ involvement" (10.4 from clinicians and 7.67 from patients $(\mathrm{p}<0.005))$.

Patients and clinicians, however, agreed about the least important issues, scoring "medication side effects" 3.6 and 3.1 respectively, "social and psychological sup port" 3.7 and 4.0, and "family planning and genetics" 3.8 and 3.6. They also agreed that research should be targeted at finding "new treatments that stop disease progression" which scored highly in both groups (9.7 in patients, 10.5 in clinicians).

Conclusions: Patients appear to feel that Raynaud's symptoms are affecting their quality of life in a way that is not being appreciated as important by clinicians. This may be due to ineffective communication between them, perhaps due to the time constraints of appointments.

Contrastingly, doctors are more concerned about avoiding organ involvement compared to patients, perhaps as they are more aware that organ involvement has a much greater effect on prognosis. However, both patients and clinicians were equally committed to investigating mechanisms of this disease.

Overall, these findings between doctors and patients should not just be a point of focus for future funding and research. It can be used to identify where there are dif ferences in expectations during clinical encounters, and therefore allow us as clinicians to tailor our agenda to better meet the needs of our patients, which would likely improve the patient-doctor relationship, enhancing communication in clinic appointments.

\section{REFERENCES:}

[1] The Lancet. Systemic sclerosis: advances and prospects. The Lancet 2017;390(10103):1624

[2] Sumpton D, Thakkar V, O'Neill S, Singh-Grewal D, Craig J, Tong A. "It's Not Me, It's Not Really Me." Insights From Patients on Living With Systemic Sclerosis: An Interview Study. Arthritis Care \& Research 2017;69 (11):1733-1742.

Disclosure of Interest: None declared DOI: 10.1136/annrheumdis-2018-eular.1556 